\title{
Editorial Comment: Comparison of pain levels in fusion prostate biopsy and standard TRUS-Guided biopsy
}

\author{
Andre Luiz Lima Diniz ${ }^{1,2}$ \\ ${ }^{1}$ Instituto Nacional do Câncer - INCA, Rio de Janeiro, RJ, Brasil; ${ }^{2}$ Hospital Federal da Lagoa, Rio de \\ Janeiro, RJ, Brasil
}

\section{COMMENT}

It is overwhelming that the concern to diagnose better is being accompanied by diagnosing carefully. We see in this article the ultimate medical art that combines technological excellence and zeal with the well-being of our patients.

Following the tendency proposed by the English study PROMISS (1) authors applied the Multiparametric magnetic resonance imaging (MpMRI) in the screening scenario, using this tool for biopsy-naïve patients. Although they recognized a bias in the allocation of individuals, the evidence of a higher detection rate in the group with PIRADS $\geq 3$ adds data to the literature and supports the indication of that refined imaging tool (2).

When fulfilling the objective of their study, the authors inform us about the similar pain potential of the technique under fusion of images in relation to the standard biopsy; demystifying one of the many questions about its use. procedures.

Despite all care taken by the team, their results reveal a major problem about the invasiveness of our

Let us remember the beginnings of the technique of image acquisition for MpMRI that included, pretty far behind, the use of endo-rectal coil (3). Certainly, in addition to being costly, impale (not to use more coarse terms) caused great discomfort to those who underwent that exam and diagnostic performance of MpMRI is not significantly different if endorectal coil is used or not (4). It didn't take long, the device is no longer part of the routine of radiology clinics, making it more acceptable to patients and recommended by urologists (5).

Prostate biopsy has long been stressful for all concerned.

Hematuria and hematochezia may cause fright and fear for the patient; but for his urologist, sepsis, prostatitis and acute urinary retention are source of great unease. Several studies have researched ways to reduce infectious complications (6) and literature proposes to understand how to turn the procedure safe and comfortable for the patient (7); and for the practitioner, faster and assertive, by improving skill acquisition techniques (8-11).

Various anesthetic approaches have been proposed and compared (12). Although the local anesthesia routes such as intrarectal local anesthesia (IRLA) and periprostatic nerve blockade (PNB) are the most common for the urologist (13), studies have assessed the suitability of total intra venous sedation (TIVS) (14). In a prospective randomized-controlled trial (RCT), Tobias-Machado et al. (15) demonstrated that application of PNB and TIVS together were associated to higher tolerance of the exam and patient comfort. In other study, authors provided TIVS alone and demonstrated a short procedure time with sufficient analgesia, allowing patients to be discharged less than 2 hours after biopsy (16). 
In a recent meta-analysis study, one of its arms evaluated the employing of sedation for transrectal prostate biopsy; evidence suggests that TIVS and PNB allows a better approach (13). In Rio de Janeiro, Brazil, at the National Cancer Institute INCa - a branch of the Department of Urology the Prostate Cancer Diagnosis Center - CDCP - routinely performs transrectal ultrasound guided biopsies of the prostate with the support of anesthetists who promote total intravenous sedation of properly monitored patients. Despite increasing the operational cost, the implementation of advanced anesthetic management makes the procedure safe and agile; by adopting the outpatient model, CDCP increased the availability of spaces for biopsies in state's public health system, with an installed capacity to perform 3600 procedures per year.

For most of the patients, several psychological factors, such as anxiety, make the procedure even more difficult $(17,18)$. Fear and embarrassment has been described as reasons for prostate biopsy refusal (19). Although the fear of pain seems obvious, it is necessary to discuss which pain the patient has the greatest aversion to. This study sheds light on this question and leads us to believe that not the needle, but the rectal introduction of a phallic object would be the main hassle factor to that individual already weakened by their cancer suspicion.

In daily urological practice, cultural aversion to digital rectal examination (DRE) is a precursor to a number of problems for the diagnosis of prostate cancer (20). We often hear from some patients the refusal to do the DRE and the exclusive acceptance of the PSA for their screening.

Paralleling the DRE, would our patients be more resentful of the offense to their masculinity caused by the ultrasound probe or does that pain really surpass that of the needle bites suffered? Qualitative studies, with adequate discourse analysis, could help us to understand this psycho-social aspect of our role (21).

In the present paper, our authors applied the most used anesthetic approach, IRLA and PNB, and

\section{CONFLICT OF INTEREST}

None declared. highlights the absence of difference in pain pattern of both sample harvesting ways. In a study of similar comparison, but with quite different methods, another group of investigators have shown that men undergoing targeted and systematic prostate biopsies experience more discomfort and anxiety during the procedure than those undergoing systematic biopsy alone (17). The psychological factor was evaluated in both studies, suggesting the importance of this issue; in this sense, sedo-analgesia plays an important role when used together with local anesthesia $(22,23)$.

Regardless of the technique used, it is important to reduce the negative impacts that our invasive methods may cause on patients. After all, the waiting line is full and it is better that they say, "with this doctor, it didn't hurt at all".

\section{REFERENCES}

1. Brown LC, Ahmed HU, Faria R, El-Shater Bosaily A, Gabe R, Kaplan RS, et al. Multiparametric MRI to improve detection of prostate cancer compared with transrectal ultrasound-guided prostate biopsy alone: the PROMIS study. Health Technol Assess. 2018;22:1-176.

2. Demirtaş A, Sönmez G, Tombul ST, Demirtaş T.Comparison of pain levels in fusion prostate biopsy and standard TRUSGuided biopsy. Int Braz J Urol. 2020;46:557-62.

3. Schnall MD, Pollack HM. Magnetic resonance imaging of the prostate gland. Urol Radiol. 1990;12:109-14.

4. Baur AD, Daqqaq T, Wagner M, Maxeiner A, Huppertz A, Renz D, et al. T2- and diffusion-weighted magnetic resonance imaging at $3 \mathrm{~T}$ for the detection of prostate cancer with and without endorectal coil: An intraindividual comparison of image quality and diagnostic performance. Eur $\mathrm{J}$ Radiol. 2016;85:1075-84.

5. Engels RRM, IsraëlB, Padhani AR, BarentszJO. Multiparametric Magnetic Resonance Imaging for the Detection of Clinically Significant Prostate Cancer: What Urologists Need to Know. Part 1: Acquisition. Eur Urol. 2020;77:457-68.

6. Pilatz A, Veeratterapillay R, Köves B, Cai T, Bartoletti R, Wagenlehner $F$, et al. Update on Strategies to Reduce Infectious Complications After Prostate Biopsy. Eur Urol Focus. 2019;5:20-8.

7. Jones JS. Minimizing Pain and Optimizing Patient Experience During Prostate Biopsy. In: Jones JS (ed.), Prostate Biopsy. Totowa, New Jersey, Humana Press. 2008; pp. 121-42.

8. Nguyen CT, Gao T, Hernandez AV, Jones JS. Can residents perform transrectal ultrasound-guided prostate biopsy with patient comfort comparable to biopsy performed by attending staff urologists? Prostate Cancer Prostatic Dis. 2010;13:52-7. 
9. Fiard G, Selmi SY, Promayon E, Descotes JL, Troccaz J. Simulation-based training for prostate biopsies: towards the validation of the Biopsym simulator. Minim Invasive Ther Allied Technol. 2019;20:1-7. Epub ahead of print.

10. Benchikh El Fegoun A, El Atat R, Choudat L, El Helou E, Hermieu JF, Dominique S, Hupertan V, Ravery V. The learning curve of transrectal ultrasound-guided prostate biopsies: implications for training programs. Urology. 2013;81:12-5.

11. Karam JA, Shulman MJ, Benaim EA. Impact of training level of urology residentes on the detection of prostate cancer on TRUS biopsy. Prostate Cancer Prostatic Dis. 2004;7:38-40.

12. Mallick S, Humbert $M$, Braud $F$, Fofana $M$, Blanchet $P$. Local anesthesia before transrectal ultrasound guided prostate biopsy: comparison of 2 methods in a prospective, randomized clinical trial. J Urol. 2004;171(2 Pt 1):730-3.

13. Kim DK, Lee JY, Jung JH, Hah YS, Koo KC, Lee KS, et al. What is the most effective local anesthesia for transrectal ultrasonography-guided biopsy of the prostate? A systematic review and network meta-analysis of 47 randomized clinical trials. Sci Rep. 2019;9:4901.

14. Turgut AT, Ergun E, Koşar U, Koşar P, Ozcan A. Sedation as an alternative method to lessen patient discomfort due to transrectal ultrasonography-guided prostate biopsy. Eur J Radiol. 2006;57:148-53.

15. Tobias-Machado M, Verotti MJ, Aragao AJ, Rodrigues AO, Borrelli M, Wroclawski ER. Prospective randomized controlled trial comparing three different ways of anesthesia in transrectal ultrasound-guided prostate biopsy. Int Braz J Urol. 2006;32:172-9; discussion 179-80.

16. Raman A, Al-Sameraaii A, Thanigasalam R, Kooner R. Patient Response to Total Intravenous Sedation (TIVS) for Outpatient Ultrasound-Guided Prostate Biopsy. UroToday Int J. 2009;02(06). Available at. <https://www.urotoday.com/ volume-2-2009/vol-2-issue-6/32558-patient-response-to-totalintravenous-sedation-tivs-for-outpatient-ultrasoundguidedprostate-biopsy-2225474.html>.

17. Wade J, Rosario DJ, Macefield RC, Avery KN, Salter CE, Goodwin ML, et al. Psychological impact of prostate biopsy: physical symptoms, anxiety, and depression. J Clin Oncol. 2013;31:4235-41.

18. Chesnut GT, Zareba P, Sjoberg DD, Mamoor M, Carlsson $\mathrm{S}$, Lee $\mathrm{T}$, et al. Patient experience of MRI-targeted prostate biopsy Patient-reported pain, discomfort, and anxiety during magnetic resonance imaging-targeted prostate biopsy. Can Urol Assoc J. 2019;29. Epub ahead of print.
19. Avery KN, Blazeby JM, Lane JA, Neal DE, Hamdy FC, et al. Decision-making about PSA testing and prostate biopsies: a qualitative study embedded in a primary care randomised trial. Eur Urol. 2008;53:1186-93.

20. Lee DJ, Consedine NS, Spencer BA. Barriers and facilitators to digital rectal examination screening among African-American and African-Caribbean men. Urology. 2011;77:891-8.

21. Turato ER. [Qualitative and quantitative methods in health: definitions, differences and research subjects]. Rev Saude Publica. 2005;39:507-14.

22. Izol V, Soyupak B, Seydaoglu G, Aridogan IA, Tansug Z. Three diferente techniques for administering analgesia during transrectal ultrasound-guided prostate biopsy: a comparative study. Int Braz J Urol. 2012;38:122-8.

23. Atta $H$, Mostafa MF, Shalaby M. Which is better for pain reduction during transrectal ultrasound-guided biopsy of the prostate: Intravenous diazepam, local periprostatic nerve block, or combination? controlled randomized study. Saudi J Anaesth. 2018;12:16-21.

Andre Luiz Lima Diniz, MD

Instituto Nacional do Cancer - INCA

Rio de Janeiro, RJ, Brasil

E-mail: andre.ufjf@gmail.com

ARTICLE INFO

Andre Luiz Lima Diniz

https://orcid.org/0000-0003-2634-412X

Int Braz J Urol. 2020; 46: 563-5

Submitted for publication: March 15, 2020

Accepted:

March 30, 2020 